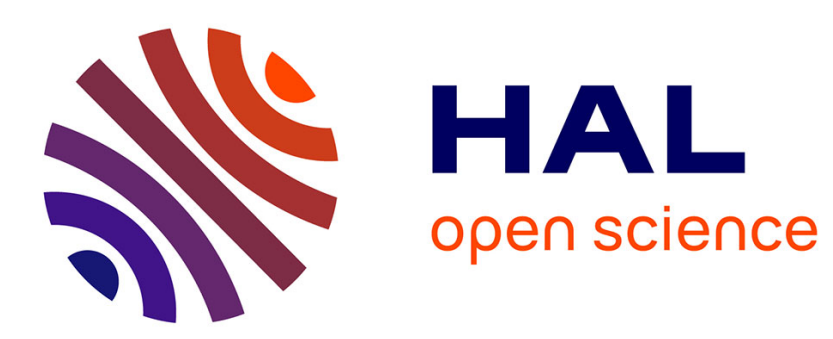

\title{
Cardiac arrhythmia induced by hypothermia in a cardiac model in vitro
}

Binbin Xu, Sabir Jacquir, Stéphane Binczak, Oriol Pont, Hussein Yahia

\section{To cite this version:}

Binbin Xu, Sabir Jacquir, Stéphane Binczak, Oriol Pont, Hussein Yahia. Cardiac arrhythmia induced by hypothermia in a cardiac model in vitro. 40th International Congress on Electrocardiology, University of Glasgow, International Society of Electrocardiology, Aug 2013, Glasgow, United Kingdom. hal-00823857v2

\section{HAL Id: hal-00823857 https://inria.hal.science/hal-00823857v2}

Submitted on 30 Aug 2013

HAL is a multi-disciplinary open access archive for the deposit and dissemination of scientific research documents, whether they are published or not. The documents may come from teaching and research institutions in France or abroad, or from public or private research centers.
L'archive ouverte pluridisciplinaire HAL, est destinée au dépôt et à la diffusion de documents scientifiques de niveau recherche, publiés ou non, émanant des établissements d'enseignement et de recherche français ou étrangers, des laboratoires publics ou privés. 


\title{
Cardiac arrhythmia induced by hypothermia in a cardiac model in vitro
}

\author{
${ }^{1}$ Binbin Xu, ${ }^{2}$ Sabir Jacquir, ${ }^{2}$ Stéphane Binczak, ${ }^{1}$ Oriol Pont, ${ }^{1}$ Hussein Yahia \\ ${ }^{1}$ Géostat, INRIA Bordeaux Sud-Ouest, 33405 Talence, France, \\ ${ }^{2}$ CNRS UMR 5158, LE2I Université de Bourgogne, Dijon France \\ Email: Binbin.xu@inria.fr
}

\begin{abstract}
Patients that have survived Out-of-Hospital Cardiac Arrest usually develop some degree of neurological problems. A common treatment to mitigate neurological damage is mild therapeutic hypothermia (MTH). However, MTH has adverse effects, including arrhythmia. In order to explore the mechanisms of arrhythmia linked to MTH, we took measures on a temperature controlled experimental model which simulates MTH. These measures consisted of extracellular potential of cardiac culture on a multi-electrode array and we analysed them in terms of nonlinear dynamics. The results showed that cardiac arrhythmia is induced around temperature $35^{\circ} \mathrm{C}$ (spiral waves at $T \sim 35^{\circ} \mathrm{C}$ against plane waves at other temperatures). A period-doubling phenomenon is also observed around $T=35^{\circ} \mathrm{C}$, confirmed with the analysis methods. All results showed that $35^{\circ} \mathrm{C}$ is a critical temperature triggering arrhythmia. This suggests that the re-warming / cooling speed could affect the arrhythmia generation after MTH.
\end{abstract}

Keywords: cardiac arrest, therapeutic hypothermia, detrended fluctuation analysis, phase space reconstruction

\section{Introduction}

The neurological damage after Cardiac Arrest (CA), caused by ischemia-reperfusion cerebral injury [1], constitutes a big health challenge. Many clinical trials with specific drugs against these damages have been conducted, however the problem remains far from being solved. Therapeutic hypothermia therapy $\left(34^{\circ} \mathrm{C}-32^{\circ} \mathrm{C}\right)$ has shown its benefit to reduce cerebral oxygen demand and improve neurological outcomes after CA [2]. Nevertheless, it can have some adverse effects, among which cardiac arrhythmia represents an important part (in up to $34 \%$ of cases, according to different clinical studies [3]). Compared to studies in vivo, cardiac culture in vitro provides a better spatial resolution at cellular level, which could bring some insights on the mechanisms of post-hypothermia arrhythmia generation.

\section{Materials}

Monolayer cardiac culture is prepared with cardiomyocytes (CM) from new-born Wistar rat (process see in Fig. 1, Left, and details of culture preparation in [4]). The extracellular potential (EP) of the CM culture is acquired with a multi-electrode array (MEA) system allowing real-time recording of the extracellular potential. The MEA has 60 electrodes aligned in a $8 \times 8$ matrix (see in Fig. 1, Right) with a diameter $30 \mu \mathrm{m}$, inter-electrodes distance $100 \mu \mathrm{m}$. Compared to other conventional electrophysiological methods (intracellular recording or by patch-clamp), this method can provide a better spatial resolution, non-toxic and non-invasive at cellular level [5], [6]. The acquired extracellular potential (EP) shares almost the same electrophysiological properties as cardiac muscular cell in situ [7], and corresponds to a combination of $1^{\text {st }}$ and $2^{\text {nd }}$ order derivatives of the action potential. In consequence, the obtained results from EP could indirectly bring some insights at cellular action potential level. 
The experiments consist of culture cooling $\left(37^{\circ} \mathrm{C} \rightarrow 30^{\circ} \mathrm{C}\right)$ and re-warming $\left(30^{\circ} \mathrm{C} \rightarrow 37^{\circ} \mathrm{C}\right)$. The acquired signals are then analysed with detrended fluctuation analysis (DFA) and phase space reconstruction (PSR).
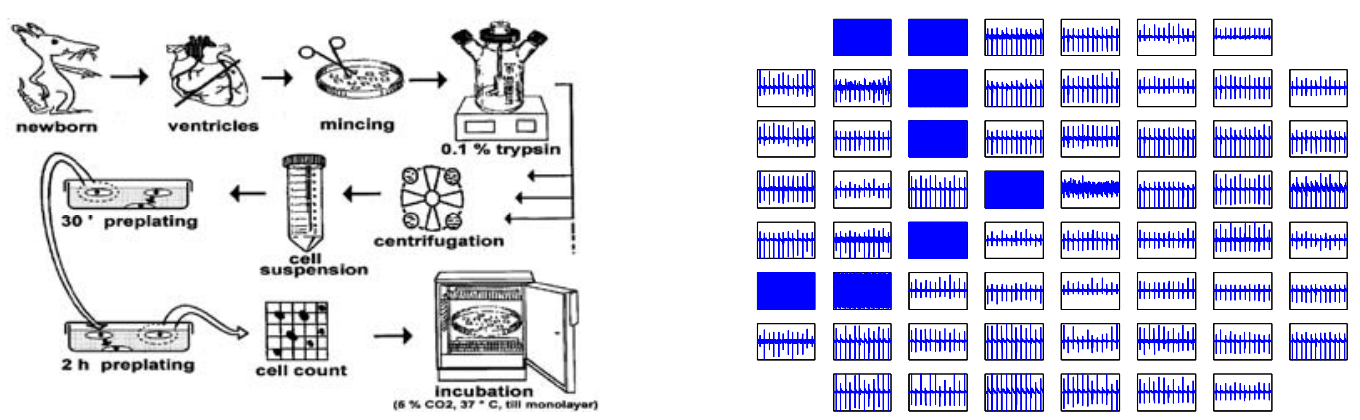

Fig. 1. Left: Preparation of monolayer cardiac culture; Right: extracellular potential acquired by MEA, 60 signals according to the positions of corresponding electrode on the MEA.

\section{Results}

\section{Arrhythmia induced by hypothermia}
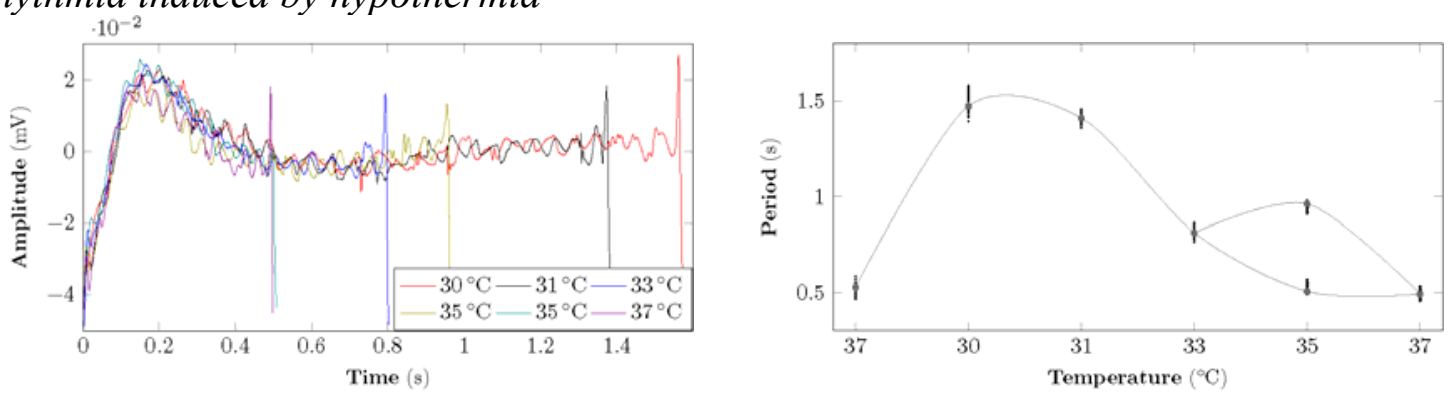

Fig. 2. Left: typical single period EP signals at different temperatures; Right: evolution of EP signal periods, periods doubling happened at $\mathrm{T}=35^{\circ} \mathrm{C}$. The small black dots show actual values, while the bigger ones are medians at each temperature.

At temperatures other than $35^{\circ} \mathrm{C}$, the EP signals are in general regular and stable. From a twodimensional view, they can be represented by the propagation of plane waves. However, at $35^{\circ} \mathrm{C}$, acquisitions show arrhythmia type signals. Spiral waves are observed in the reconstructed activation map which is commonly considered as a sign of cardiac arrhythmia. Both experiments (re-warming and cooling) showed that period-doubling phenomena happened at this temperature (see Fig. 2), which can be interpreted as a transition point from a normal state to a chaotic state. We also observe an inflection point between $30^{\circ} \mathrm{C}-33^{\circ} \mathrm{C}$, which could indicate another regime transition of different nature than the first one; in accordance to other studies showing that hypothermia below $32^{\circ} \mathrm{C}$ induces arrhythmia [2]. These signals are then analysed by methods DFA and PSR.

\section{Detrended fluctuation analysis}

DFA is a method for determining the statistical self-affinity of a signal, which is often used to analyze electro-physiological signals [8]. DFA characterizes the degree of complexity of the EP signals. This property is expressed as a parameter D which gives a measure of the effective (fractal) dimension of the system. As shown in Fig. 3, the result confirmed that a doubling of values happened at $35^{\circ} \mathrm{C}$, almost exactly as observed in Fig. 2. 

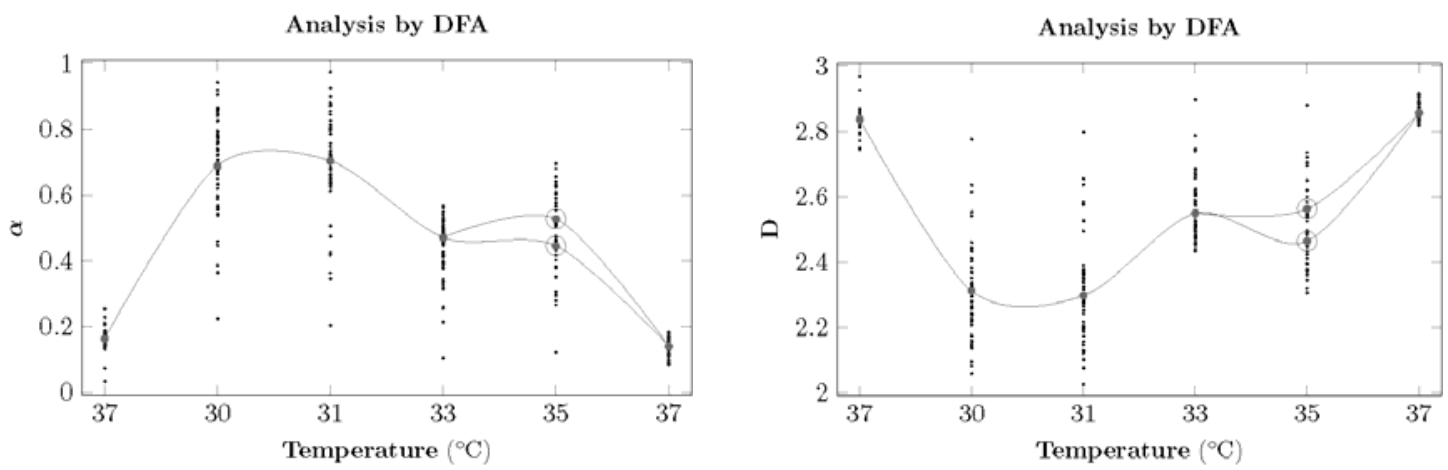

Fig. 3. Detrended fluctuation analysis for EP signals, showing the values for parameters $\alpha$ and D (which equals $3-\alpha$ ). Parameter doubling happened at $\mathrm{T} \sim 35^{\circ} \mathrm{C}$.

\section{Phase space reconstruction}

Another method from chaos theory and nonlinear dynamics, which is suitable to study the complex dynamics of physiological signals, is the phase space reconstruction. Its principle is to transform the properties of a time series into topological properties of a geometrical object which is embedded in a space, wherein all possible states of the system are represented. Each state corresponds to a unique point, and the reconstructed space shares the same topological properties as the original phase space of the system behind the observed time series [9].
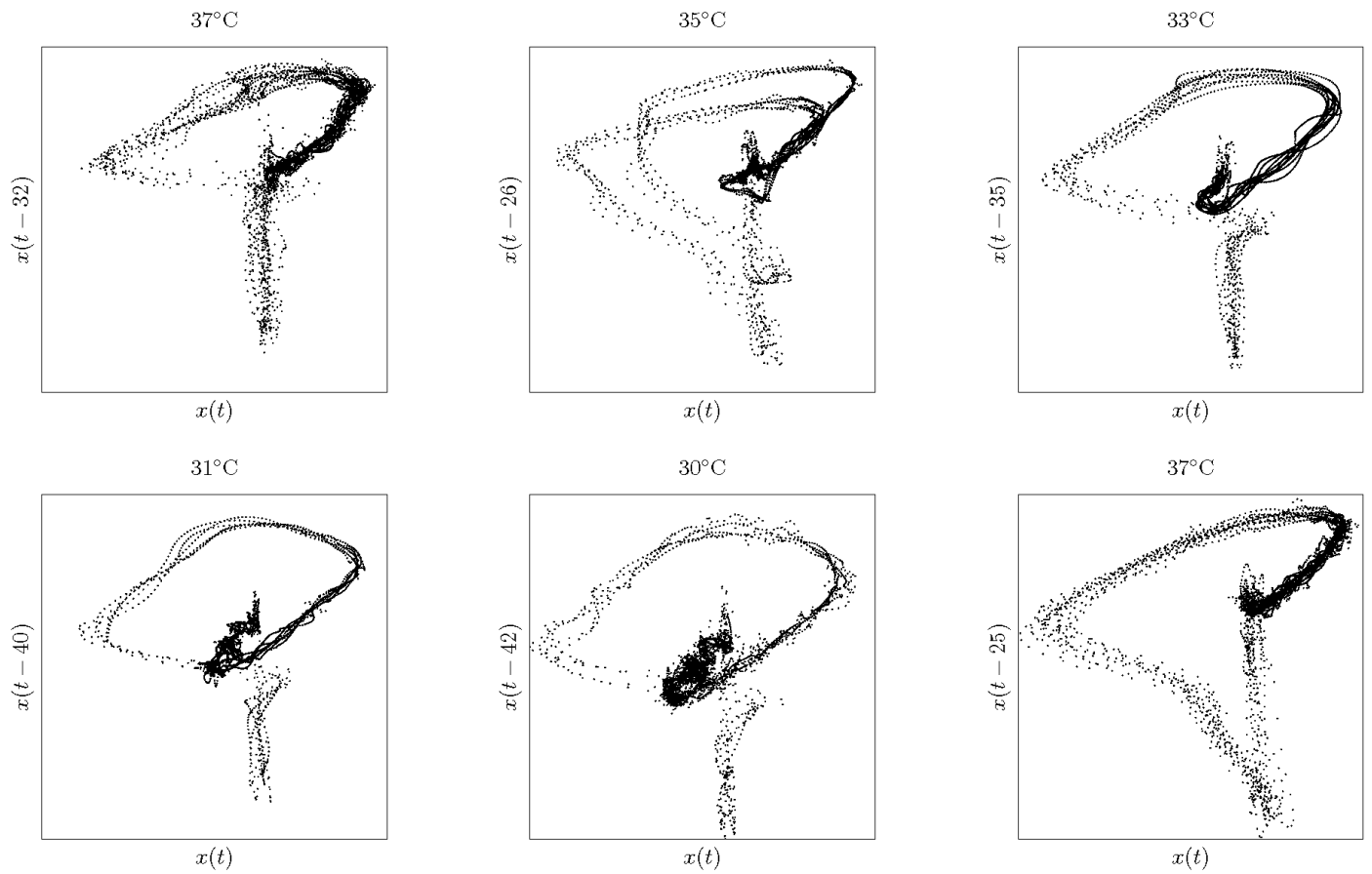

Fig. 4. Phase space reconstruction for signals at different temperatures $\left(37^{\circ} \mathrm{C} \rightarrow 30^{\circ} \mathrm{C} \rightarrow 37^{\circ} \mathrm{C}\right)$. A trajectorydoubling is observed at $\mathrm{T}=35^{\circ} \mathrm{C}$.

The trajectories of EP signals are represented in the reconstructed phase space (Fig. 4). Their general forms are similar. The width of these trajectories is tight, which signifies that the system is stable. However around $\mathrm{T} \sim 35^{\circ} \mathrm{C}$, a bifurcation of trajectories is observed which reflects the fact of periods-doubling as shown in Fig. 1. These results further confirmed in a more concrete way that $\mathrm{T} \sim 35^{\circ} \mathrm{C}$ could be a critical temperature for arrhythmia generation after the therapeutic hypothermia. 


\section{Conclusions}

In this experimental study, the action potentials during the process of therapeutic hypothermia (cooling and re-warming) are generally stable except around $\mathrm{T} \sim 35^{\circ} \mathrm{C}$. At this temperature, cardiac arrhythmia type signals are induced and spiral waves can be observed in the culture against plane waves at other temperatures. Also at this temperature, the activation periods are doubled, which indicates a transition to chaotic dynamics. Both analysis methods DFA and PSR confirmed a singular behaviour around $\mathrm{T} \sim 35^{\circ} \mathrm{C}$. The general hypothermia therapy uses constant rate of cooling and re-warming. From our observations, we propose that varying this rate, especially when passing around $35^{\circ} \mathrm{C}$, could reduce the possibility of post-hypothermia arrhythmia generation.

\section{Acknowledgements}

We acknowledge the Institute of Cardiovascular Research (Dijon, France) and the NVH Medicinal (Dr. David VANDROUX, Dijon, France) for our collaboration in the experimental data acquisition.

\section{References}

[1] de Vreede-Swagemakers JJ, Gorgels AP, Dubois-Arbouw WI, van Ree JW, Daemen MJ, et al. (1997). Out-of-hospital cardiac arrest in the 1990s: A population-based study in the maastricht area on incidence, characteristics and survival. Journal of the American College of Cardiology 30: 1500-1505.

[2] Group W, Nolan J, Morley P, al (2003). Therapeutic hypothermia after cardiac arrest: An advisory statement by the advanced life support task force of the international liaison committee on resuscitation. Circulation 108: 118-121.

[3] HACA (2002). Mild therapeutic hypothermia to improve the neurologic outcome after cardiac arrest. New England Journal of Medicine 346: 549-556.

[4] Athias P, Vandroux D, Tissier C, Rochette L (2006). Development of cardiac physiopathological models from cultured cardiomyocytes. Annales de Cardiologie et d'Angeiologie 55: 90-99.

[5] Stett A, Egert U, Guenther E, Hofmann F, Meyer T, et al. (2003). Biological application of microelectrode arrays in drug discovery and basic research. Analytical and Bioanalytical Chemistry 377: 486-495.

[6] Hescheler J, Halbach M, Egert U, Lu ZJ, Bohlen H, et al. (2004). Determination of electrical properties of es cell-derived cardiomyocytes using meas. Journal of Electrocardiology 37: 110-116.

[7] Watanabe T, Delbridge LM, Bustamante JO, McDonald TF (1983). Heterogeneity of the action potential in isolated rat ventricular myocytes and tissue. Circulation Research 52: 280-90.

[8] Kantelhardt JW, Zschiegner SA, Koscielny-Bunde E, Havlin S, Bunde A, et al. (2002). Multifractal detrended fluctuation analysis of nonstationary time series. Physica A: Statistical Mechanics and its Applications 316: 87-114.

[9] F. Takens. Detecting strange attractors in turbulence, in Dynamical Systems and Turbulence, Lecture Notes in Mathematics (D. Rand and L.-S. Young, eds.), vol. 898, pp. 366-381, Springer Berlin / Heidelberg, 1981. 